\title{
Leading the charge: Identifying stressors in nursing leadership
}

\author{
Shauna Keil, Michelle Van Der Wege, Patricia Drees \\ Fort Hays State University, United States
}

Received: March 19, 2019

Accepted: May 24, 2019

Online Published: June 2, 2019

DOI: $10.5430 /$ cns.v7n3p12

URL: https://doi.org/10.5430/cns.v7n3p12

\begin{abstract}
Objective: This study aimed to examine and identify specific stressors for charge nurses at a rural Midwestern hospital. Methods: The Charge Nurses Stress Questionnaire (CNSQ) was administered to charge nurses of all units at a small Midwestern hospital. A total of 30 charge nurses completed the survey. The charge nurses completed 25 questions on four stress subscales, in addition to 11 demographic questions.

Results: Study results revealed the highest stressors were primarily related to being unable to meet patient needs. This situation includes when a nurse cannot reach the provider when an urgent patient need arises; when the unit is at capacity with high acuity patients and receives notification another patient has been assigned to the unit; and when the patient is in pain or otherwise suffering, and care is delayed because orders are needed.

Conclusions: Stress was noted by all charge nurses. The levels of different stressors from subscales correlate with each other, and thus an increase in one subscale of stress directly affects the level of stress of another subscale. The level of stress among charge nurses was not statistically significant among the nurses of different age, different units, different shifts, and different years of experience.
\end{abstract}

Key Words: Charge Nurse, Stress, Nurses, Nursing

\section{INTRODUCTION}

There is no question that nursing is a stressful profession. Staff shortages, increasing workloads, cumbersome facility requirements, inefficient technology processes, and the absence of effective pathways for nurses to implement improvements contribute to the stress inherent to nursing. These stressors have a negative impact on job satisfaction and ultimately may contribute to the decision to leave the profession. ${ }^{[1]}$ Several studies have suggested various factors that contribute to the development of work-related stress, in addition to those listed above, these include job complexity, high responsibility, inadequate leadership, and difficult nurse-doctor collaboration. ${ }^{[2]}$ Nurses are expected to pro- vide high quality, safe healthcare in working environments where limited resources and increasing responsibilities are common. ${ }^{[3]}$

The IOM (2010) challenges the nursing profession to create leaders to increase the level of quality in the healthcare system. Often the leaders of hospital units are the charge nurses-they are the frontline managers of the units. The complex role of the charge nurse is crucial for effective management of hospital units. ${ }^{[4]}$ Obtaining an understanding of the stress these nurses experience can help to impact patient care positively. ${ }^{[5]}$

The charge nurse has a dual role: managerial and clinical. ${ }^{[4]}$

*Correspondence: Shauna Keil; Email: slkeil@ fhsu.edu; Address: Fort Hays State University, United States. 
Charge nurses are expected to lead staff while managing the work processes on the assigned unit to ensure the needs of patients are met. ${ }^{[6]}$ Responsibilities of charge nurses include patient outcomes, patient safety, staff well-being, multidisciplinary team management, and enforcement of organizational policy. ${ }^{[5]}$ Charge nurses impact the satisfaction of patients and nurses, risk management, physician relations, and the patient discharge process. ${ }^{[7]}$ Previous studies have focused on nursing staff in general, and little research has been conducted on the specific stressors of a charge nurse. In light of the many important functions of charge nurses, it is important to identify and address the stressors of this unique role; the purpose of this study was to accomplish that goal.

The Charge Nurse Stress Questionnaire (CNSQ) was developed in 2015 by Admi, Eilon, Renker, and Unhasuta. Previous tools utilized to analyze stress were often scales that were not specific to nursing. The measurement by the CNSQ utilizes the specific stress situations typical of this role, and items were defined through the identification of gaps between a specific demand and a resource. ${ }^{[4]}$

\section{Methods}

The study design was a descriptive study that utilized selfreported survey data. Data were collected from a total of 30 nurses from a small Midwestern hospital who completed the Charge Nurses Stress Questionnaire in May of 2018. Charge nurses surveyed worked on a variety of units within the hospital including medical/surgical, obstetrics (OB), the intensive care unit (ICU), the emergency room (ER), cardiac progressive care unit (CPCU) and orthopedics. Statistical analyses were performed using the SPSS statistical package, version 23. Descriptive statistics including frequencies, means, and standard deviations were determined. Independent T-Tests were used to determine stress levels among different shifts. ANOVA tests were conducted to determine stress among charge nurses on different units, of different ages, and with different years of experience. A bivariate correlation analysis was done to determine relationships between levels of stress.

Approval was granted the Institutional Research Board of the small Midwestern hospital as well as the university. Recruitment was invited via email with a link to a protected survey on Survey Monkey. Participation was voluntary, and consent was implied by completing the questionnaire. Inclusion criteria included being a registered nurse who served as a charge nurse on any unit in the hospital, were able to read and write in English, and were willing to complete the survey.

The instrument used was the Charge Nurse Stress Questionnaire. The CNSQ is a 25-item questionnaire designed to measure charge nurse stress. It is a summated Likert-type instrument with each item scored 1 (very little), 2 (little), 3 (moderate), 4 (great) to 5 (very much). The four subscales of the CNSQ are patient and family complaints (nine items), lack of resources (seven items), responsibility/burden (four items) and professional conflict (four items). Initial tests of internal consistency of the cross-cultural CNSQ produced a Cronbach's alpha coefficient of greater 0.93-0.95. [5]

\section{Results}

The majority of the charge nurses were female (90\%). Approximately $26.67 \%$ were 30 years or younger, $26.67 \%$ were 31 to $40,23.33 \%$ were 41 to $50,17.57 \%$ were 51 to 60 , and only two charge nurses $(6.67 \%)$ were above the age of 60 . The majority of charge nurses worked on the medicalsurgical floor $(26.67 \%$ ), while $20 \%$ worked in OB, $16.67 \%$ worked in each the orthopedic unit and CPCU, and $10 \%$ each worked in the ER and the ICU.

As shown in Table 1, nursing experience varied. The majority of charge nurses had only been a nurse on the unit for 2 to 5 years $(50 \%)$.

Table 1. Charge nurse experience

\begin{tabular}{llll}
\hline Items & & Frequency & Percent \\
\hline & Up to 5 years & 6 & 20.0 \\
& 6-10 years & 6 & 20.0 \\
Experience as a Nurse & $11-15$ years & 8 & 26.7 \\
& 16-20 years & 1 & 3.3 \\
& More than 20 years & 9 & 30.0 \\
& Up to 5 years & 8 & 26.7 \\
Experience in Current & 6-10 years & 10 & 33.3 \\
Unit & $11-15$ years & 4 & 13.3 \\
& 16-20 years & 2 & 6.7 \\
& More than 20 years & 6 & 20.0 \\
& Up to 1 year & 2 & 6.7 \\
Experience as a & 2-5 years & 15 & 50.0 \\
Charge Nurse in the & 6-10 years & 5 & 16.7 \\
Current Unit & 11-15 years & 1 & 3.3 \\
& 15 years & 7 & 23.3 \\
& Total & 30 & 100.0 \\
\hline
\end{tabular}

Seventy percent of the charge nurses had a bachelor degree, whereas $30 \%$ had an associate degree. The majority of charge nurses also took a patient assignment in addition to his or her charge nurse duties (82.76\%). Most of the charge nurses work on the acute (medical-surgical) unit $(26.67 \%, \mathrm{n}=8)$, whereas $20 \%(n=6)$ worked on the obstetrical unit, $16.67 \%$ $(\mathrm{n}=5)$ worked on each the orthopedic unit and cardiac progressive care unit, and $10 \%(n=3)$ worked in the intensive care unit or emergency room.

As shown in Table 2, a reliability analysis was conducted using Cronbach's Alpha. This test evaluates the level of con- 
sistency of data collected from the questionnaire. From the analysis, it is evident that all the variables had the acceptable level of Cronbach's Alpha with all values above 0.7.

\subsection{Patient and family complaints}

Conflict with family, specifically when the family had issues with nursing care, ranked highest among patient and family complaints. Other issues with patients and family that ranked near the top were being blamed for things of which the nurse has no control. Overall, complaints with patients and families contributes a moderate amount of stress to charge nurses (see Table 3).

\subsection{Lack of resources}

Lack of resources, including personnel and orders, is another source of stress for charge nurses. The urgent need for a physician ranks among the highest of all questions in the survey. Other sources of stress in this area include working with inexperienced staff while caring for a client at high risk for complications and receiving negative feedback from a supervisor in spite of putting forth one's best efforts. Overall, this area was a significant source of stress for the nurses in this study (see Table 4).

Table 2. Reliability analysis

\begin{tabular}{lllll}
\hline Subscale & No. of items & Mean & SD & Cronbach’s Alpha \\
\hline Patient and family complaints & 9 & 2.9958 & .68974 & .859 \\
Lack of resources & 7 & 3.7905 & .89705 & .917 \\
Responsibility/burden & 4 & 3.600 & .81485 & .888 \\
Professional conflict & 4 & 3.4417 & .87268 & .820 \\
\hline
\end{tabular}

Table 3. Patient and family complaints

\begin{tabular}{|c|c|c|}
\hline Items & Mean & SD \\
\hline $\begin{array}{l}\text { The patient's family complained angrily to you about the behavior of a nurse. You know the nurse did the } \\
\text { right thing and it is hard for you to handle the family. }\end{array}$ & 3.60 & .932 \\
\hline A patient's family is angry and blames you for things over which you have no control. & 3.40 & 1.133 \\
\hline A patient is complaining about another team member. The patient is right and you do not know how to react. & 3.03 & .964 \\
\hline Although you are trying to admit a new patient as fast as you can, the patient loses patience and yells at you. & 3.00 & 1.050 \\
\hline You must tell a patient that their surgery or testing is delayed. The patient gets angry with you. & 2.97 & .890 \\
\hline $\begin{array}{l}\text { Someone promised a patient that they could move to a more comfortable room. However, you cannot } \\
\text { accommodate the move. }\end{array}$ & 2.93 & 1.015 \\
\hline A patient has a concern that you can solve. However, the patient insists on talking only with their physician. & 2.57 & .858 \\
\hline $\begin{array}{l}\text { You answer a patient's question. You are frustrated when the patient only wants to hear the same information } \\
\text { from their physician. }\end{array}$ & 2.47 & .900 \\
\hline
\end{tabular}

Table 4. Lack of resources

\begin{tabular}{lll}
\hline Items & Mean & SD \\
\hline $\begin{array}{l}\text { You urgently need the physician on duty and cannot find him or her. } \\
\text { A patient's condition is getting worse and there could be complications. The nurses working with you do not } \\
\text { have the knowledge to help you. }\end{array}$ & 3.27 & 1.048 \\
$\begin{array}{l}\text { Although you are working hard to put forth your best efforts, the unit supervisor finds something negative } \\
\text { about what you are doing. }\end{array}$ & 3.80 & 1.196 \\
$\begin{array}{l}\text { You are working with another nurse. That nurse does not complete their tasks. The result is chaos on the unit. } \\
\text { You arrive for your shift and receive a phone call from a nurse who should already be at work. The nurse }\end{array}$ & 3.73 & 3.67 \\
$\begin{array}{l}\text { advises that he/she is not coming due to illness. } \\
\text { The doctor on duty gives you an instruction that does not fit your knowledge and clinical experience. }\end{array}$ & 3.63 \\
\begin{tabular}{l} 
You must be home on time but cannot leave the unit when you need to. \\
\hline
\end{tabular} & 3.57 & 1.129 \\
\hline
\end{tabular}




\subsection{Responsibility/Burden}

The next area of stress is the area of responsibility and burden. The highest ranking item is this section was regarding having a full census of high acuity patients and being notified of an admission. Another source of stress involves acting as both the charge nurse and caring for patients, as it is a challenge to address the problems on the unit as well as provide quality patient care (see Table 5).

Table 5. Responsibility/Burden

\subsection{Professional conflict}

Finally, the last area of stress that was studied was personal conflict. The highest ranking item in this section is when a patients needs cannot be met due to a lack of orders. Another component of stress in regards to personal conflict involves workplace violence; when a nurse is threatened and needs help, it causes concern for staff and personal safety (see Table 6).

\begin{tabular}{lcc}
\hline Items & Mean & SD \\
\hline The unit is full and has high acuity patients. Suddenly you are notified that you are receiving another new patient. & 4.13 & .937 \\
As the one in charge you are having a hard time delivering direct patient care and solving unit problems at the & 3.83 & .874 \\
same time. & \\
A patient's condition is getting worse. You are worried that something will happen to the patient, solely because & 3.67 & 1.093 \\
you were not able to take over all required tasks to help them. & 3.47 & 1.196 \\
You collected a lot of data on your shift and are afraid you forgot something important. & 3.37 & 1.098 \\
At the end of your shift you feel you were not successful in completing all tasks. & 3.13 & .860 \\
A few problems occur all at once. You are having a hard time deciding what to do first. &
\end{tabular}

Table 6. Professional conflict

\begin{tabular}{|c|c|c|}
\hline Items & Mean & SD \\
\hline $\begin{array}{l}\text { A patient is suffering greatly and there is no physician on the unit. You know what to do but are not allowed to do } \\
\text { so without first obtaining orders from the physician. }\end{array}$ & 3.70 & 1.236 \\
\hline $\begin{array}{l}\text { A nurse on your team wants your help after being threatened by a patient's family. You are also worried about } \\
\text { the threat. }\end{array}$ & 3.57 & 1.006 \\
\hline You arrive home after a shift and remember you forgot to do something important. & 3.47 & 1.106 \\
\hline You are having a hard time implementing acquired professional values in managing patient care. & 3.03 & .964 \\
\hline
\end{tabular}

\subsection{Correlation of variables}

The descriptive statistics indicate the stress level was high among charge nurses when there is lack of resources (mean $=3.79$ ), whereas responsibility/burden contributed to mean of 3.6, the professional conflict had a mean of 3.44, and patient and family complaints had the lowest stress levels with a mean of 2.99. Independent $t$-test was conducted to determine the mean difference between stress levels among nurses in different shifts. From the analysis, it is evident that there is no significant difference between the stress levels among the charge nurses in the different shifts with the $p>$ .05 .

An ANOVA test was conducted to determine the significant mean difference between the various levels of stress and different units on which charge nurses work. From the analysis, it is evident there is no significant difference between the different units and the stress levels, with the $p>.05$. An ANOVA test was conducted to determine the significant mean difference between the different levels of stress and

Published by Sciedu Press age of the charge nurses. From the analysis, it is evident there is no significant difference between experience and the stress levels, with the $p>.05$ (see Table 1). An ANOVA test was conducted to determine the significant mean difference between the different levels of stress and experience as a nurse in the current unit and as a charge nurse. From the analysis, it is evident there is no significant difference between experience as a nurse in the current unit or as a charge nurse and the stress levels, with the $p>.05$.

Bivariate correlation analysis was conducted to determine if there is any significant relationship between different levels of stress. From the analysis, it is evident there is significant relationship between patient and family complaints with lack of resources, with correlation $r=.662, p<.01$; responsibility/burden with correlation $r=.699, p<.01$; and professional conflict with correlation $r=.743, p<.01$. There is also a significant positive association between lack of resources and responsibility/ burden with the correlation $r=.804, p<.01$, and professional conflict with the correlation coefficient $r=$ 
$.851, p<.01$. The stress levels as a result of the responsibil- as a result of the professional conflict with the correlation ity/burden are also positively correlated to the stress levels coefficient $r=.829, p<.01$, as shown in Table 7 .

Table 7. Bi-variate correlation analysis

\begin{tabular}{|c|c|c|c|c|c|}
\hline Items & & $\begin{array}{l}\text { Patient and family } \\
\text { complaints }\end{array}$ & $\begin{array}{l}\text { Lack of } \\
\text { resources }\end{array}$ & $\begin{array}{l}\text { Responsibility } \\
\text { /burden }\end{array}$ & $\begin{array}{l}\text { Professional } \\
\text { conflict }\end{array}$ \\
\hline \multirow{3}{*}{$\begin{array}{l}\text { Patient and family } \\
\text { complaints }\end{array}$} & Pearson Correlation & 1 & $.662^{* *}$ & $.699^{* *}$ & $.743^{* *}$ \\
\hline & Sig. (2-tailed) & & .000 & .000 & .000 \\
\hline & $\mathrm{N}$ & 30 & 30 & 30 & 30 \\
\hline \multirow{3}{*}{ Lack of resources } & Pearson Correlation & $.662^{* *}$ & 1 & $.804^{* *}$ & $.851^{* *}$ \\
\hline & Sig. (2-tailed) & .000 & & .000 & .000 \\
\hline & $\mathrm{N}$ & 30 & 30 & 30 & 30 \\
\hline \multirow{3}{*}{ Responsibility/burden } & Pearson Correlation & $.699^{* *}$ & $.804^{* *}$ & 1 & $.829^{* *}$ \\
\hline & Sig. (2-tailed) & .000 & .000 & & .000 \\
\hline & $\mathrm{N}$ & 30 & 30 & 30 & 30 \\
\hline \multirow{3}{*}{ Professional conflict } & Pearson Correlation & $.743^{* *}$ & $.851^{* *}$ & $.829^{* *}$ & 1 \\
\hline & Sig. (2-tailed) & .000 & .000 & .000 & \\
\hline & $\mathrm{N}$ & 30 & 30 & 30 & 30 \\
\hline
\end{tabular}

Note. ${ }^{* *}$ Correlation is significant at the 0.01 level (2-tailed).

\section{Discussion}

Most of the charge nurses are worried when he or she cannot find the physician or provider when one is urgently needed; when the unit is full or has high acuity patients, and a new admission is necessary; and when the patient is suffering, but there is no physician on the unit, meaning little can be done to relieve the suffering without first obtaining orders from the physician.

Also, the level of various types of stress is not different among the nurses of diverse ages, nurses working in different units or shifts, or have different years of experience. The levels of different stress are correlated with each other, and thus an increase in one level of stress directly affects the level of stress of another. For instance, the lack of resources will automatically affect or increase the patient and family complaints. The stress of charge nurses impacts patient care and the health of the staff. A decrease of stress will benefit patients, staff, the organization, and the nursing profession.

The stressors that were identified have a common theme nurses want to take the best possible care of his or her patients. Charge nurses have the additional burden of also wanting to take the best possible care of the unit staff and peers. High-quality patient care is everyone's goal, and thus reducing the stress in doing so benefits everyone from patients to healthcare organizations.

To positively impact the stress that affects nurses while doing their jobs, it is important to understand what those stressors are. This influence begins with the charge nurses as they are the leaders of each unit. If the charge nurses do not have the resources needed to manage the unit, neither will the staff nurses. Charge nurses are in a unique position be on the frontlines of patient care delivery, as well as the supervision and management of every nurse and patient on the unit at any given time. While it is not reasonable to think all of these stressors can be eliminated, it is important to mitigate as many as possible. This study helps to identify those stressors that impact charge nurses the most.

Examination of the results indicates professional collaboration can be a significant source of stress for charge nurses. This process includes reaching a provider when needed, as well as tense interactions between providers and nurses. To alleviate some of this stress, all facilities must work to improve interprofessional collaboration. Also, methods to improve communication between providers and nurses must also be addressed.

Another recurring theme in this data is the stress that a lack of resources causes to charge nurses. Unfortunately, the continuing nursing shortage and high turnover make this a very difficult problem to solve. One in five nurses changes jobs in the first year and one in three by the end of year two. ${ }^{[8]}$ The best way to improve the availability of resources - specifically the most valuable resource, which is nurses themselves - is to look at ways to improve the workplace and reduce the stress encountered while caring for patients. 


\section{Limitations and suggested research}

The authors recognize there are limitations to this study. The study used a convenience sample of nurses from a rural, Midwestern hospital. Due to the small sample size, this should be considered a pilot study. The results of this study lead to several opportunities for future research. The results may not be generalizable to other hospitals because of the small sample size, and single site of research. Additional studies to evaluate the stressors in a variety of settings would help to determine what stressors are universal, and those that are unique to individual settings. Furthermore, research aimed at identifying interventions is important. Research to evaluate the use of interventions to reduce stress in different settings would help to identify recommendations for nurses in those settings. This may include large and small hospitals and/or different units of the hospital.

\section{Conclusion}

In conclusion, numerous charge nurse stressors have been identified. These stressors center on meeting the needs of patients to ensure the highest quality of care. The ability to reach a physician or provider for necessary orders, the inability to relieve pain and suffering, and the stress of caring for both patients and peers are all sources of stress for charge nurses. Nurses, administration, and providers must work together to reduce these areas of stress where possible. Ultimately, this will lead to better patient care.

\section{Conflicts of InTEREST Disclosure}

The authors declare they have no conflicts of interest.

\section{REFERENCES}

[1] Future of Nursing, at the Institute of Medicine. The Future of Nursing: Leading Change, Advancing Health. Washington (DC): National Academies Press (US); 2011. PMid:24983041. https: //doi.org/10.17226/12956

[2] Van Bogaert P, Adriaenssens J, Dilles T, et al. Impact of role-, joband organizational characteristics on nursing unit managers' work related stress and well being. J Adv Nurs. 2014 Jan; 70(11): 2622-33. PMid:24842679. https://doi.org/10.1111/jan.12449

[3] Khamisa N, Oldenburg B, Peltzer K, et al. Work related stress, burnout, job satisfaction and general health of nurse. Int $\mathrm{J}$ Environ Res Public Health. 2015; 12(1): 652-66. PMid:25588157. https://doi.org/10.3390/ijerph120100652

[4] Admi H, Yael E. Do hospital shift charge nurses from different cultures experience similar stress? An international cross-sectional study. Int J Nurs Stud. 2016 Aug; 63: 48-57. PMid:27591723. https://doi.org/10.1016/j.ijnurstu.2016.08.005
[5] Admi H, Eilon Y, Renker P, et al. Stress measurement among charge nurses: developing a cross-cultural tool. J Adv Nurs. 2015 Jan; 72(4): 926-35. PMid:26537013. https://doi.org/10.1111/jan.1284 5

[6] Sherman R, Schwrazkpof R, Kiger A. Charge nurse perspectives on frontline leadership in acute care environments. ISRN Nurs. 2011 Aug; 1-8. PMid:22191051. https://doi.org/10.5402/2011/1 64052

[7] Krugman M, Heggem L, Kinney L, et al. Longitudinal charge nurse leadership development and evaluation. J Nurs Adm. 2013 Sept; 43(9): 438-46. PMid:23979034. https://doi .org/10.1097/NN A. $0 \mathrm{~b} 013 \mathrm{e} 3182 \mathrm{a} 23 \mathrm{~b} 26$

[8] Kovner C, Brewer C, Fatehl F, et al. What does nurse turnover mean and what is the rate? Policy, Politics Nurs Prac. 2014; 15(3-4): 64-71. PMid:25156041. https://doi .org/10.1177/15271544145479 53 